\title{
Interactive activities to stimulate debate and critical thinking about issues related to Earth sciences and sustainable development
}

\author{
Alessandra Magagna ${ }^{\star}$ Elena Ferrero, Cristina Giannatempo
}

Università di Torino, Dipartimento di Scienze della Terra, Torino, Italy

\author{
Article history \\ Received December 21, 2011; accepted March 1, 2012. \\ Subject classification: \\ Earth science education, Sustainable development, Exhibition, Action research, Critical thinking.
}

\begin{abstract}
During the International Year of Planet Earth (2007-2009), the Department of Earth Sciences of Turin University and a local Museum of Natural History promoted a project entitled, Understanding how the Earth works: from local situations to global processes. In this context, two geothematic exhibitions on the Cape Verde Archipelago were designed and staged in local museums. The exhibition called Getting to know a volcano in order to live with it was the subject of action research that involved the design of interactive activities and the analysis of data collected during guided tours conducted with students of different ages. This study allowed the demonstration of the effectiveness of teaching strategies in which relevant Earth sciences topics are proposed, like risk and sustainable development, thus stimulating debate among the students. This approach enhances the cultural experience of individuals by sharing it with other people. The aim was to widen their awareness of the cultural value of the territory, and to stimulate a new critical way of thinking about the Earth sciences. These didactic tools were further developed when they were proposed and pursued by experienced museum guides and teachers, who were able to involve not only institutions (museums and schools) in the knowledge construction process, but also families, relatives and the local community.
\end{abstract}

\section{Introduction}

The Department of Earth Sciences of Turin University, together with the Craveri Natural History Museum (in Bra, Cuneo, Italy), promoted the project Understanding how the Earth works: from local situations to global processes. This was performed during the International Year of Planet Earth (2007-2009). The project originated from the many activities of cooperation and partnership jointly undertaken by the Piemonte Region and the Cape Verde Republic over the last few decades, which has allowed visits and the studying of the geology and culture of the Cape Verde Archipelago. During these years, many experiences of the twinning schools of Piemonte with those of Cape Verde were carried out. This has given the pupils involved the chance to learn about a culture and a territory that is different from their own, through photographs, paintings, objects, games, essays and teleconferences [Ferrero et al. 2006, 2007].

All of these experiences have increased our awareness of the importance of comparing different realities in order to know more about our own territory, both in terms of its resources and risks. At the same time, this approach allows us to widen public awareness about the cultural value of our territory, and to broaden the childrens' minds towards a new critical way of thinking about the Earth sciences. For these reasons, two geothematic exhibitions on Cape Verde were designed in Piemonte [Ferrero et al. 2009a, 2009b].

\section{Aims and goals}

The main purposes of the project were:

- to reveal the charm and beauty of the Earth sciences;

- to highlight the importance of the Earth sciences for human activities;

- to create awareness of the role of humankind as a modifying agent of the landscape;

- to provide a global approach to problems, starting with an analysis of local situations;

- to provide a scientific dimension to the various issues, without neglecting the educational aspects of knowledge transmission.

Particular attention was given to the didactic approach and the ways of communication. The project Understanding how the Earth works: from local situations to global processes was an excellent opportunity to design and test new didactic tools that could be used to help visitors to develop their awareness and critical thinking about Earth sciences issues and sustainable development [Carrada 2006].

\section{Exhibitions and educational offers}

The two traveling exhibitions were entitled Getting to know a volcano in order to live with it, and Treasures and secrets of the coastal environment. These show two emblematic situations of the Cape Verde territory (the volcanic, 
and the coastal environments) and compare them with the corresponding Italian ones, in terms of the need for enhancement and protection of the geological heritage. Special attention was focused on the constant interactions between the natural environments and human activities. In this context, particular care was given not only to the geological endogenous and exogenous processes, which contribute to landscape evolution and natural hazards, but also to the impact generated by human activities, on both the local and global scales. All of these themes suggested a comparison between the Italian and the Cape Verde areas.

The topics covered by both of the exhibitions were highly interdisciplinary and can be addressed to different age brackets, according to the level of detail achieved by the students. Indeed, the exhibitions were equipped with guided tours and practical laboratories, which were addressed to students of different ages (from nursery, to secondary school), as well as workshops dedicated to in-service teachers (www.caboverde.com) [Ferrero and Ranzenigo 2009]. The local community was introduced to the exhibitions through a series of conferences and selfguided tours (Figure 1).

\section{Action research project}

The exhibition Getting to know a volcano in order to live with it included three sections:

- Geological structures and geomorphology;

- Volcanic activity and risks;

- Natural resources and environmental sustainability.

The groups were invited to choose one section. They could integrate the guided tour with a preliminary workshop focused on the rock and a final geomorphological workshop.

This exhibition (from February-April 2008) was the object of an action research program that was based on the design of interactive activities and the analysis of data collected during the program. The aim was to assess the effectiveness of the interactive activities proposed, and to establish possible modifications during their performance, as well as in view of future events.

Action research is a kind of qualitative research that aims to improve the teaching practice during and after the research [Elliott 1993]. The action research program was planned as the following steps:

- teachers and students were informed that they were part of an action research project promoted by the University of Turin, Italy;

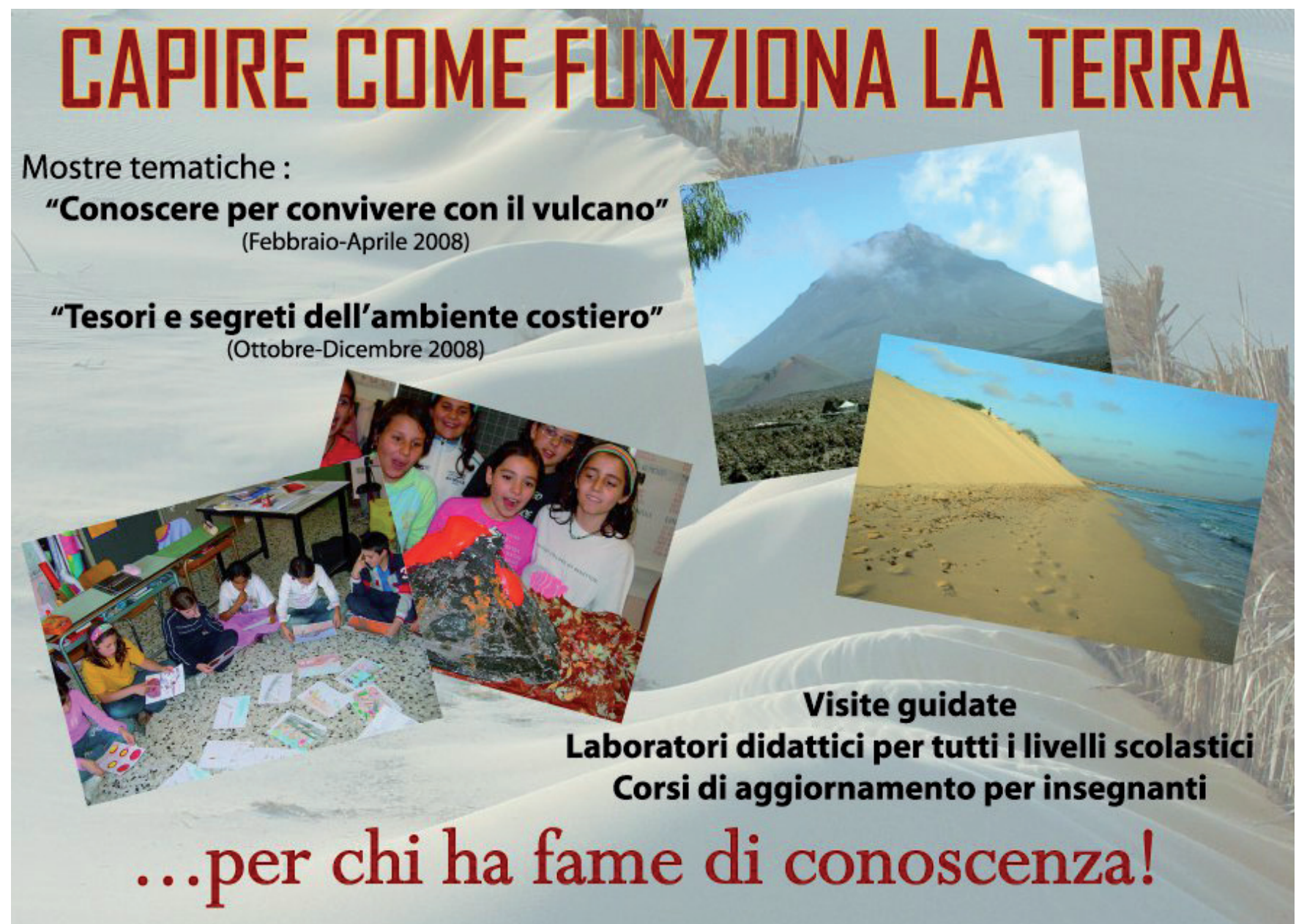

Figure 1. The exhibitions were promoted by flyers and guidebooks. 
KNOWLEDGE DERIVES FROM DAILY LIFE

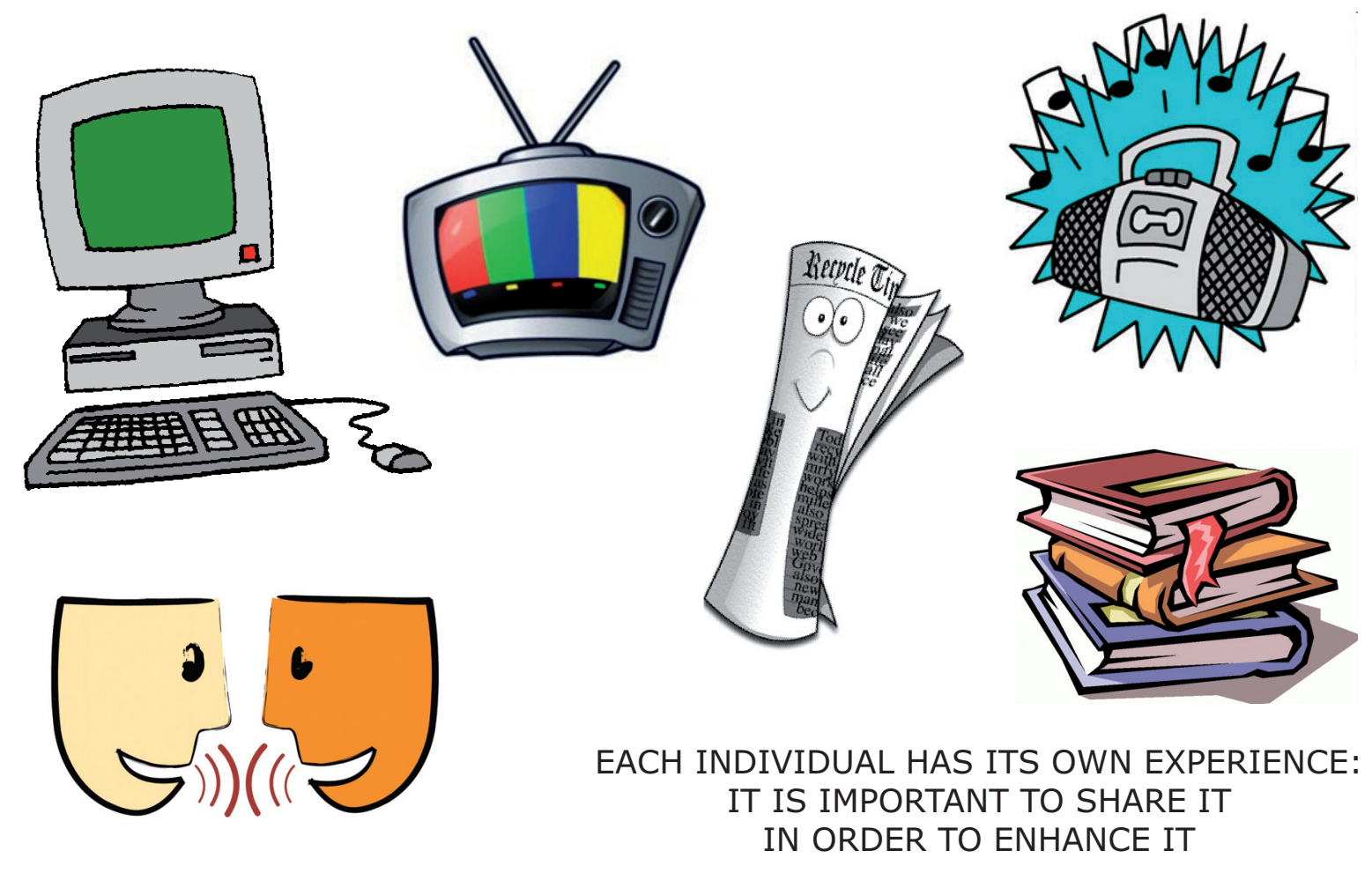

Figure 2. Main sources of information from daily life.

- the students were required to write out their answers and reflections during the activities, and the teachers were invited to participate with them;

- everybody filled in a satisfaction questionnaire at the end of the program;

- the teachers were asked to support the research and to express their opinions on the didactic approach proposed in the visits;

- the final workshop included a discussion about the data that was collected during the interactive activities and was analyzed by the researchers;

- a conference disseminated the results of the action research program to all parties.

This approach, together with the teaching strategies adopted, was intended to involve the teachers and the students as much as possible in the action research, to widen the interactions between the researchers and the others involved in the experience. The researchers acted as participant observers [Pimenta 2005]: they guided the visits and moderated the discussions, based on the features of the groups, and the monitoring of the activities.

Considering that in Italy most guided tours in museums and classroom lectures consist of the giving of information, this project proposed a different way to approach the teaching/learning process. The ambitious aim was to make the teachers and students experience that there is a more effective way to learn, based on:
- personal experience and the previous cultural experience;

- comparison and reflection with others;

- emotional involvement.

This approach was designed to expand both the researchers' knowledge and the level of awareness of the groups considered [Pimenta 2005].

\section{Interactive activities}

The interactive activities were designed on the assumption that everybody has their own cultural experience, which should to be shared to acquire new knowledge and skills [Ferrero and Gimigliano 2007]. Starting from this personal experience, a process of knowledge construction can be stimulated (Figure 2).

The exhibition Getting to know a volcano in order to live with it is based on a geoethic approach to Earth sciences and proposes reasoning from local situations to global processes. Starting from their own experience, visitors were asked to reflect on the differences and similarities of the geological features in different localities. In this context, the interactive activities were aimed to promote cultural enrichment of the visitors by generating emotional involvement, stimulating interest and curiosity [Goleman 1995], developing debate, and widening the view points on topics of relevant scientific and social value (Figure 3 ).

The educational activities included tests with open or multiple-choice questions, to trigger a process of discov- 
ery that was driven by the availability of multiple interpretations. There were no ready answers to the questions posed, so the answers can and should be constructed from reflective practice.

During the interactions, each individual carries out his/her own learning process, stimulated by an inductive process of discovery. The visitors try to understand the problem posed, and to develop hypotheses and to test them, until they reach an inference. In this way, everybody acquired a personal experience, rather than factual information [Compiani 2007]. The inferences reached were useful to widen the vision from local situations to global processes, to detect the network of relation-

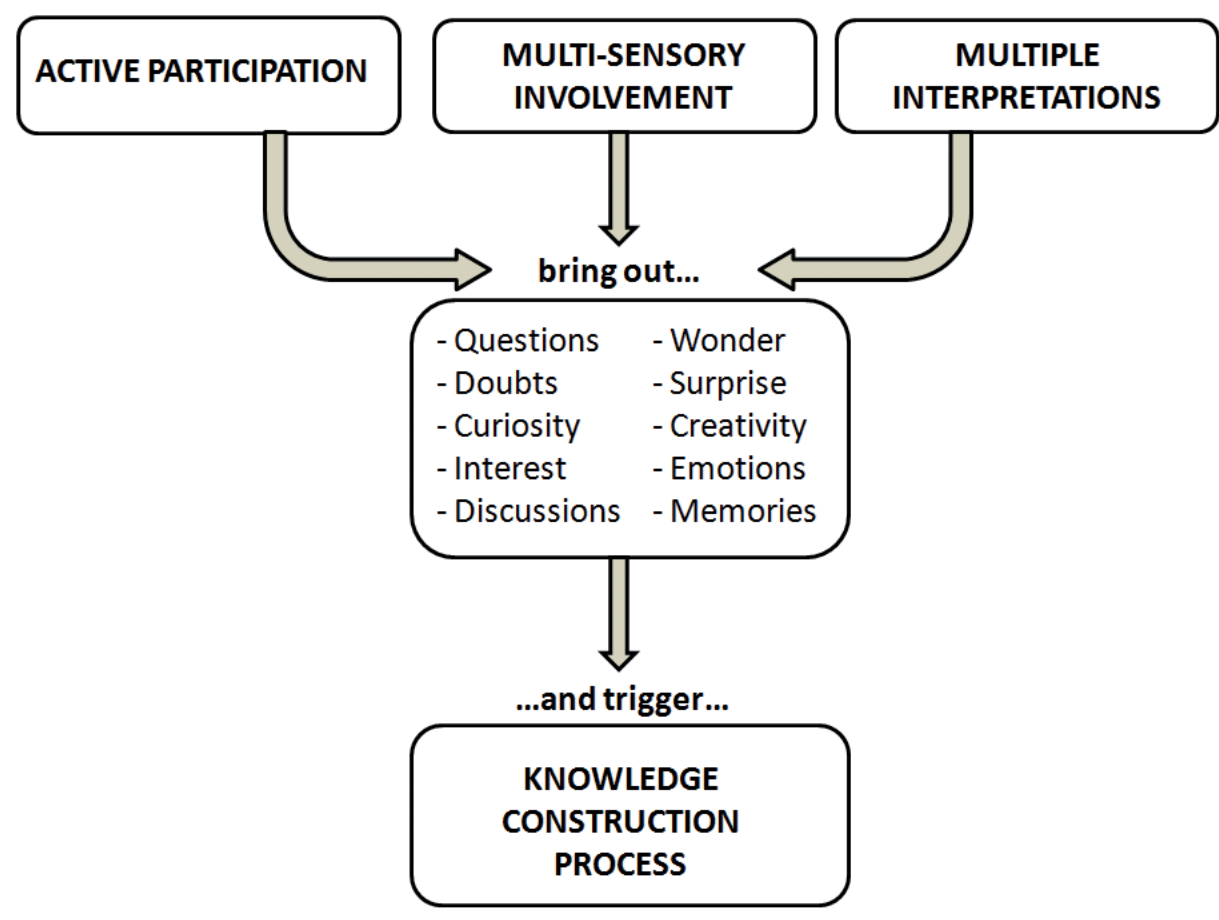
ships between events and prod-

Figure 3. Contribution of interactive activities to the knowledge construction process. This approach is useful to widen the attention from a local to a global scale. ucts. In this process, emotional involvement is crucial, because it makes the experience remarkable due to the esthetic, ethical, historical and everyday life suggestions [Ghose 2000, Wagensberger 2000, Vomero and Merzagora 2001].

\subsection{What is a volcanic island?}

In the section of geological structures and geomorphology, the students had to answer the question "What is a volcanic island?" and to draw a volcanic island. Although this activity was designed to introduce the geomorphology section, the drawings always showed elements that were useful to discuss risks and environmental sustainability (Figure 4). The multiplicity of an-
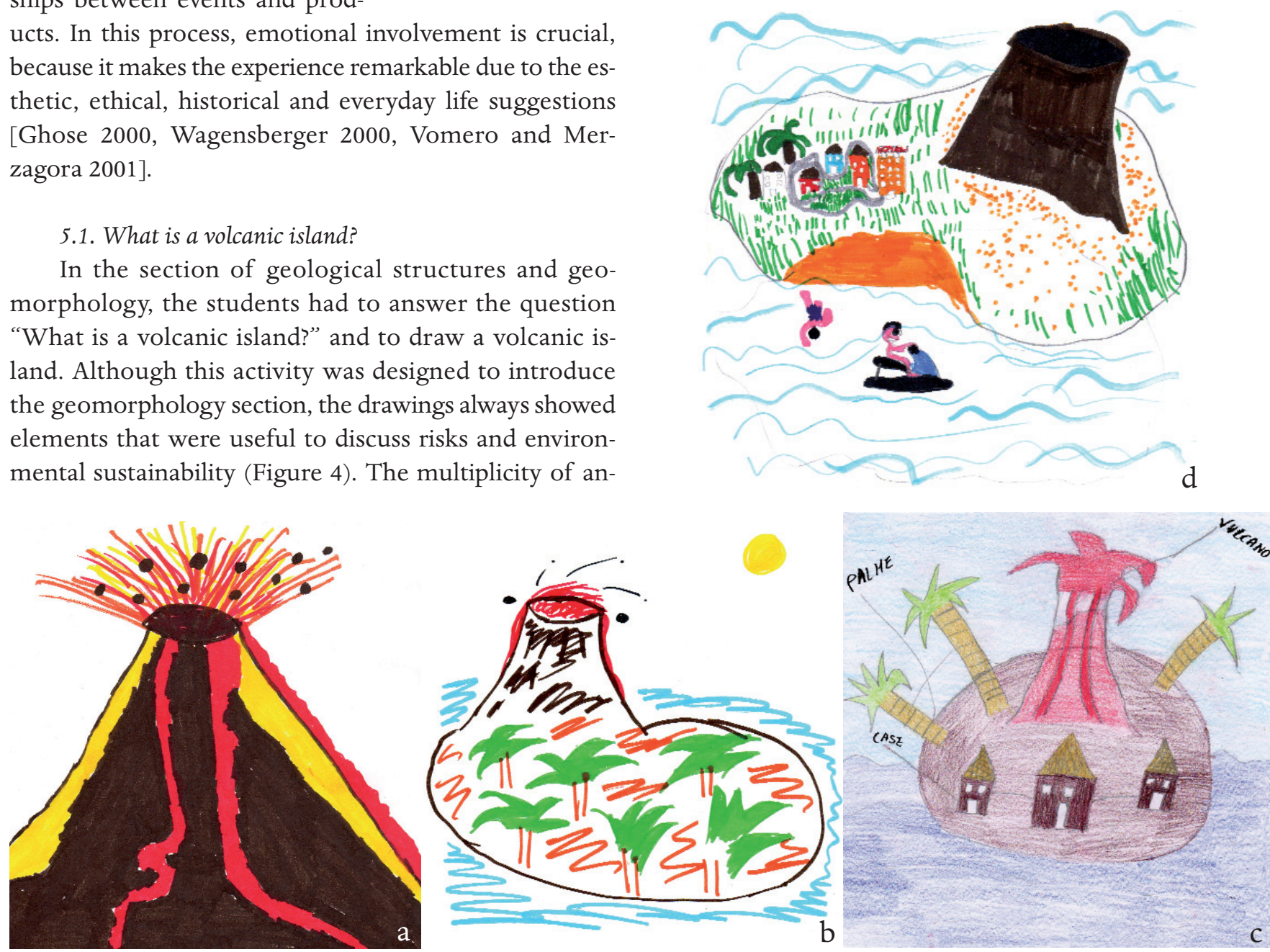

Figure 4. Selected drawings. (a) The attention is focused on the volcanic structure and its activity. (b) The eruption and the vegetation are the main subjects in this drawing. (c) Volcanic activity and human settlements stimulated a discussion of the volcanic risk. (d) The presence of a tourism site allowed talk about the environmental impact on the island. 
swers obtained allowed the comparison of the volcanic activity and risk in Italy and Cape Verde.

\subsection{Sounds, risks and resources}

This interactive activity related to the section on volcanic activity and risks, and proposed that they listen to six sounds (sea waves, a storm, the wind, a volcanic eruption, a rock drill, and stream water) and to express the emotions they felt during this listening. Then, the students were asked:

- to guess which event produced each sound;

- to give their opinion on the consequences of each event;

- to reflect on the possible risks connected with the events (Figure 5).

\subsection{Scenes related to... "From local to global"}

Six scenes were proposed in the section on natural resources and environmental sustainability, which suggested: water and energy consumption, rubbish accumulation, air pollution, drought, biological resources recruitment (Figure 6). Here the students were asked:

- to describe the situation illustrated by each scene;

- to indicate whether the situations were considered eco-friendly;

- to locate each scene as being in Italy or in Cape Verde, or in both countries.

\section{Results}

During the interactive activities, the students filled out the worksheets prepared by the researchers, to collect their answers. A semi-quantitative method was applied to analyze the data [Crabtree and Miller 1992]. This method allowed the identification of a set of categories within the answers given by the students, and the quantification of their frequency [Silvermann 2004, Robson 2005]. The results showed various mental representations and multiple viewpoints of the topics discussed.

A multiple choice satisfaction questionnaire collected the opinions of the students on the visit. The researchers, who had the role of museum guides, monitored the levels of interest and participation of the students and teachers during the visits, and reported their observations as a multiple choice questionnaire. Finally, the teachers who followed both the visit and the workshops with their students completed a satisfaction questionnaire.

Overall, throughout three months of research, more than 30 classrooms visited the exhibition and filled in these questionnaires. Due to the amount of data collected (more than 600 questionnaires), 189 questionnaires filled in by the students were analyzed (corresponding to 11 groups). The selection of items that are the most significant for each questionnaire are reported here.
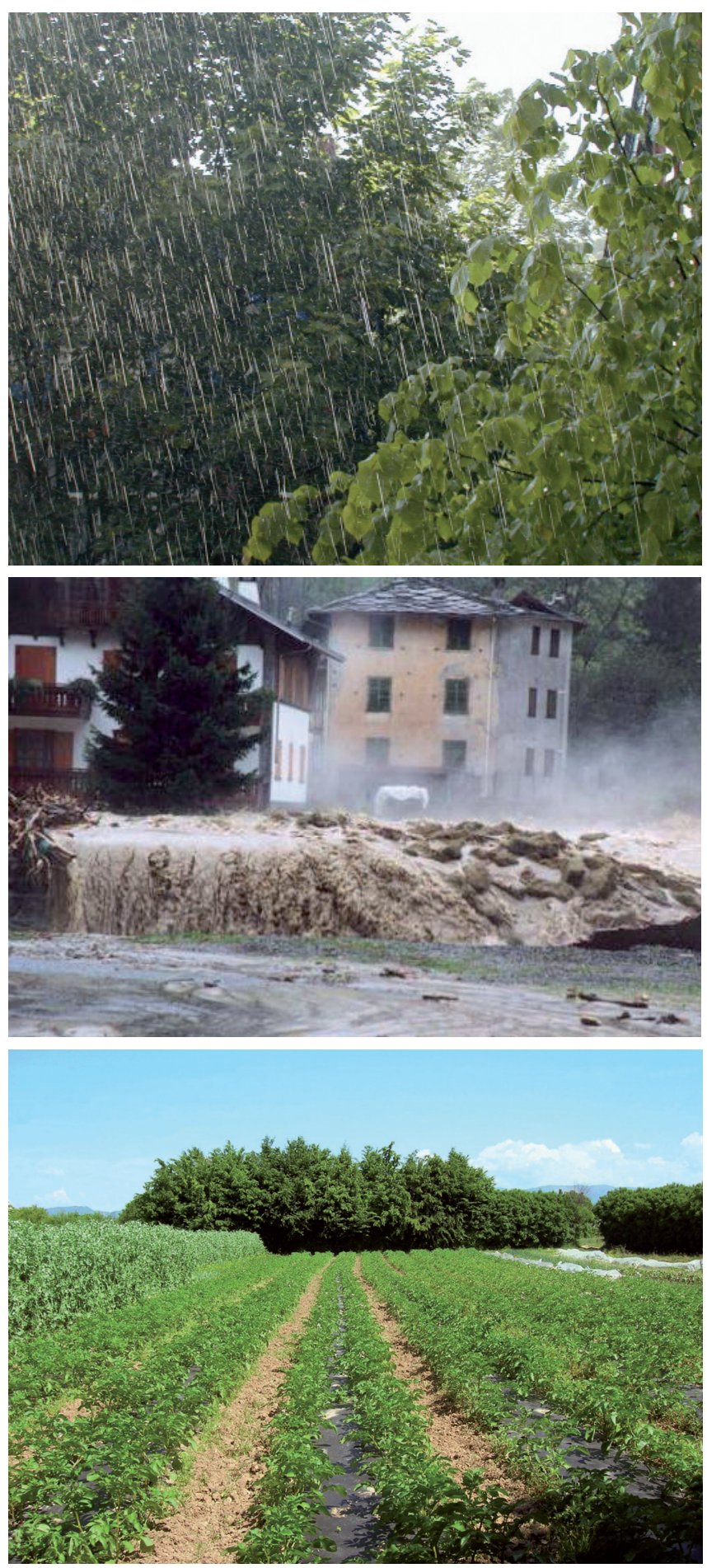

Figure 5. Listening to the sound of a storm evocates either a flood or the watering of the land. These effects can be considered positive or negative, depending on the season and the territory involved.

a) Students: Would you like to come back to visit the exhibition?

Yes $(90 \%)$. Most of them would like to come back with their classmates or with their relatives.

b) Museum guides/researchers: Did the interactive activities stimulate interest and curiosity?

Yes (91\%). Even the less-motivated students participated in the discussions. 

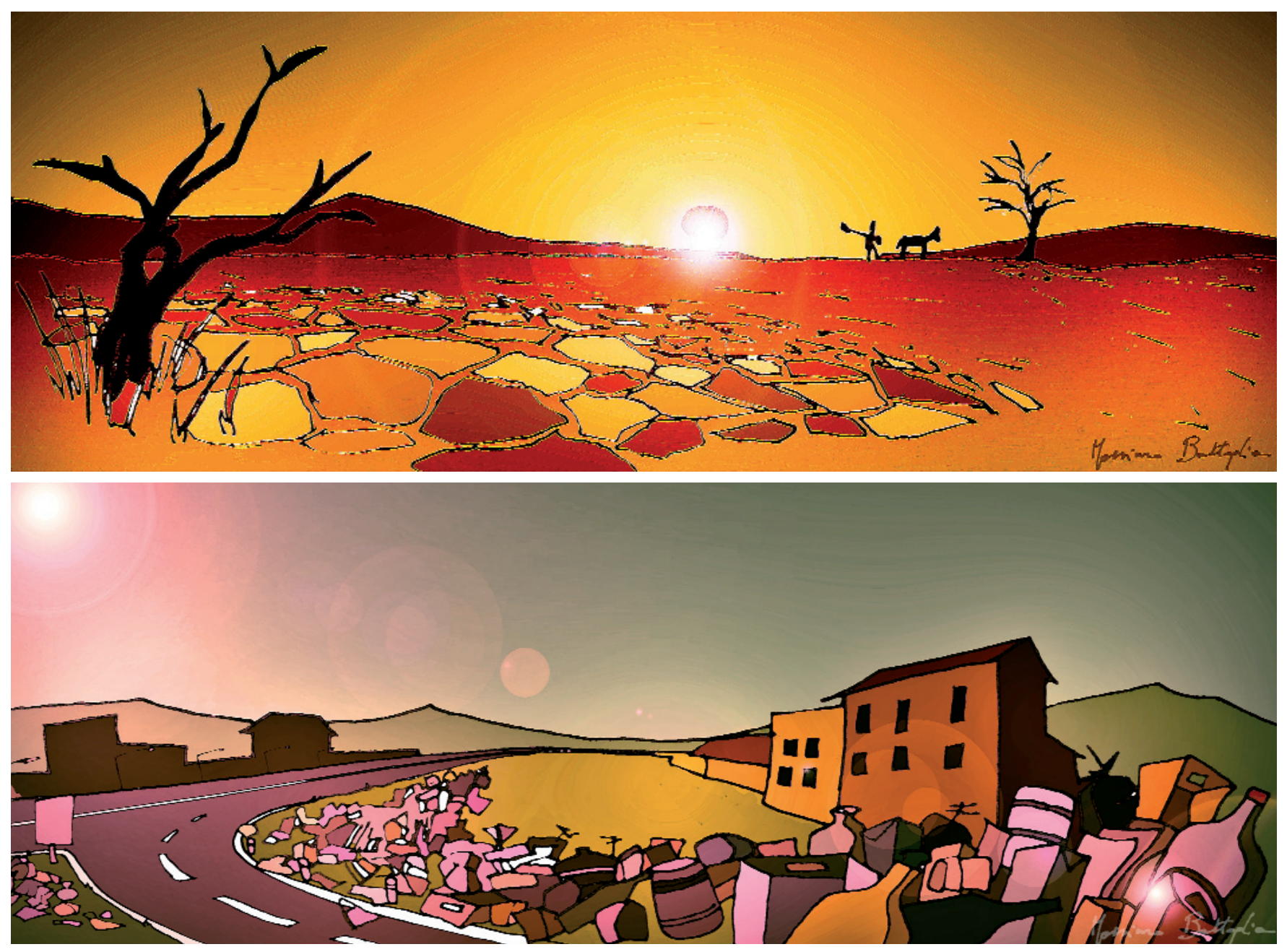

Figure 6. Selected scenes. Top: In all, 95\% of students located the drought scene in Cape Verde, suggesting discussions on droughts in Italy and on the implications of global warming. Bottom: The rubbish scene was located in Italy (50\%); and also both in Italy and Cape Verde (30\%). The results show that rubbish accumulation is perceived as a global problem that is managed in different ways in different countries.

c) Teachers: Was the exhibition enjoyable? Was it useful for learning the topics proposed?

Yes, it was enjoyable (100\%). Yes, it was useful $(85 \%)$. The educational strategy satisfied both teachers and students.

Through the collaboration of some of the teachers, it was possible to have feedback concerning the positive implications of the pedagogical strategies adopted during the visits in the later classroom work. The students attitude for curiosity and investigation was stimulated by the researchers, and it was favored and promoted by the teachers in the classroom. One case history refers to the teachers and the students of a Primary School. Starting from the visit of a few classes to the exhibition Getting to know a volcano in order to live with it, all of the students of the school were involved in a wider project of environmental education based on the local and global approach. Through this experience, the teachers learned:

- to share the growth opportunities with their students;

- to accept that some answers can be unknown;

- to accept with respect the suggestions and assumptions of their students, viewed as possibilities to learn together [Compiani 2007].

\section{People and values}

"Action research assumes that the subjects involved constitute a group with common objective and goals, interested in a problem that emerges from a given context in which they have various roles. With the problem established, the role of the researcher is that of helping the group to problematize it, that is, to locate it in a wider theoretical context, and therewith allow the growth of the conscience of those involved, with a view to plan the forms of transformation of the subjects' actions and institutional practices" [Pimenta 2005]. This means that action research projects require an experienced research team and a high level of awareness about the project. For these reasons, a relevant aspect of the present research consists of the involvement of the actors from the planning to the conclusion.

The exhibition was designed by a multidisciplinary team of teachers and researchers who are experts in natural sciences and geology, and all of whom have a remark- 
able science teaching background. The museum guides were involved in the planning phase and asked to share ideas, values and knowledge with the scientific committee. So, the exhibition tours were led by operators aware and involved not only in the contents, but in the values to be transmitted. During the activities, the museum guides moderated the discussions, helping both students and teachers with debate as well as with personal reflection.

The interpersonal relationships that occurred among museum guides, students and teachers during the guided tours provided the best evidence of the effectiveness of the interactive teaching strategies adopted. For example, the guided tours stimulated interest in the topics discussed. This was demonstrated both during the visits, through questions and observations (Figure 7), and in the classrooms, through the request for further details.

Some special cases did allow us to investigate these aspects and they demonstrated that the right involvement of the students in the constructive discussions stimulated critical thinking and new ways to approach the topics. Such a favorable situation can be promoted in schools by experienced teachers, who can develop and refine teaching strategies that allow the understanding of complex and abstract concepts, going beyond the traditional lecture in which descriptions and memorization of situations prevail. In most cases, the best projects promoted from the teachers involved not only institutions such as museums and schools, but also families, relatives, friends and the local community. For this reason, at the end of the project, a conclusive meeting was organized, where the results of the action research program were shown to all parties.

The involvement of many and diverse people in a project might be the right way to provide new practice to introduce complex issues such as natural resources use, risk prevention, and enhancement and protection of the geosphere.

\section{Conclusions}

This study shows that teaching strategies can make a difference in knowledge construction processes. It is important to stimulate people to compare situations and to share ideas, so as to enable them to take a stand about complex topics. This can be done through didactic strategies and tools that stimulate curiosity, wonder, interest, doubts and emotions, and that involve everybody's personal experience.

Both of the exhibitions that were designed during the International Year of Planet Earth were staged at different locations, where the activities were offered again, with positive feedback. They are still available to be staged in new places and the activities can also be re-proposed outside the context of the exhibition they were conceived for.

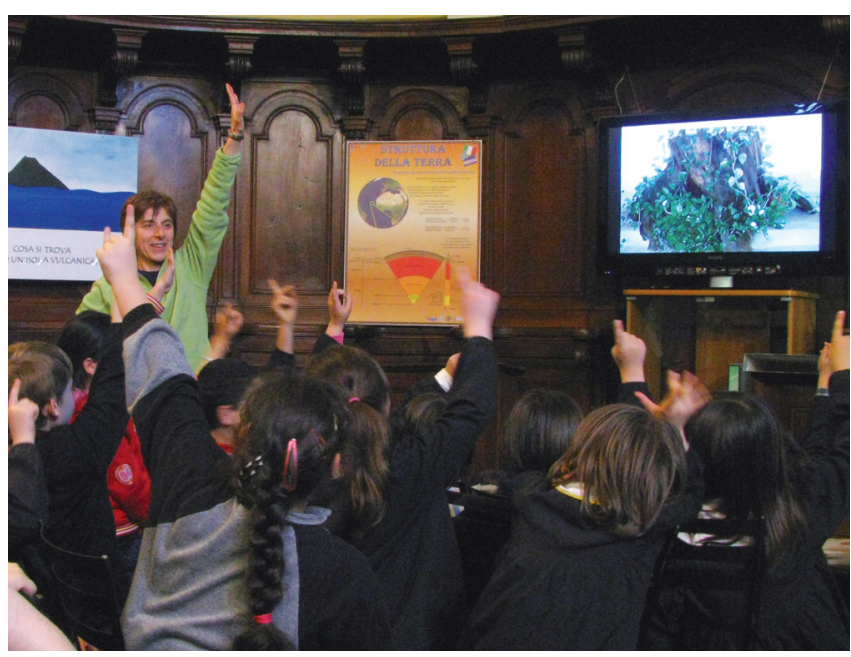

Figure 7. Children express their opinions about the geological processes.

Acknowledgements. This study was conducted as part of the activities of the pilot project Understanding how the Earth works, which was promoted and funded by the Craveri Museum of Natural History in Bra (Cuneo, Ialy), by the City of Bra, and by the Department of Earth Sciences, Turin University, with contributions from various private and institutional sponsors, and with $60 \%$ MIUR funds to $\mathrm{E}$. Ferrero. The pilot project is part of a wider project of dissemination of the geological culture Earth Sciences for Society, which was sponsored by UNESCO for the International Year of Planet Earth (2008). We are very grateful to the hundreds of visitors, and particularly to the students and teachers who contributed with their active participation in the production of the huge amount of experimental data that has been examined and in the validation of the didactic proposal.

\section{Data and sharing resources}

Carrada, G. (2006). Communicating science: a scientist's survival kit, Office for Official Publications of the European Communities, Luxembourg, 76. This article can be downloaded from the webpage http:/ / ec.europa.eu/research/ science-society/pdf/communicating-science_en.pdf.

Pimenta, S.G. (2005). Critical-collaborative action research: constructing its meaning through experiences in teacher education, Educ. Pesqui., São Paulo, 31. This article can be downloaded from the webpage: http:/ / dx.doi.org/10.1590/S1517-97022005000300013.

The contents of the exhibitions are available on:

http://www.caboverde.com/nature/vulcani.htm, http://www.caboverde.com/nature/ coste.htm.

\section{References}

Compiani, M. (2007). O lugar e as escalas e suas dimensões horizontal e vertical nos trabalhos práticos: implicações para o ensino de ciências e educação ambiental, Ciência \& Educação, 13, 29-45.

Crabtree, B.F. and W.L. Miller (1992). Primary care research: a multi-method typology and qualitative road map, In: Doing Qualitative Research, B.F. Crabtree and W.L. Miller (eds.), Thousand Oaks, California, USA, SAGE Pubbl., 276. 
Elliott, J. (1993). Ricerca-Azione: teoria e pratica, In: La ricerca-azione. Metodiche, strumenti e casi, G. Pozzo and Zappi L. (eds.), IRRSAE Piemonte, Italy.

Ferrero, E., A. Cappa, P. Lovesio, R. Prando, E. Molinaro and G. Mortara (2006). Proposte di educazione alla sostenibilità attraverso un progetto di gemellaggio e cooperazione, In: Atti del 3rd World Environmental Education Congress, Torino, Italy, 121-125.

Ferrero, E., and D. Gimigliano (2007). Le Concezioni Spontanee nelle Scienze della Terra. Vulcani, terremoti ed alluvioni visti dagli allievi della scuola primaria e secondaria, Regione Piemonte - Settore Affari Internazionali e Comunitari, Sistema di Cooperazione Decentrata, Comune di Refrancore Ed., 55.

Ferrero, E., D. Gimigliano and G. Mortara (2007). Perception des risques géologiques à travers un parcours interculturel. Jumelage entre les écoles du Piemont (Italie) et de la République du Cap Vert, Actes $4^{\mathrm{e}}$ Colloque Interuniversitaire Turin-Sahel, Université Abdou Moumouni de Niamey, Niger, 282-293.

Ferrero, E., and A.C. Ranzenigo (2009). Conoscere per convivere con il vulcano, Comune di Bra Ed., 67.

Ferrero, E., A. Magagna, M. Morando, A.C. Anzenigo and Ranzenigo, A. Ruggiero and G. Mortara (2009a). Developing intercultural consciousness in school children: interaction between schools and museums, In: Proceedings of 4th International Congress on Science and Technology for the Safeguard of Cultural Heritage in the Mediterranean Basin, Cairo, 1, 447-452.

Ferrero, E., A. Magagna, A.C. Ranzenigo, avec la collaboration de E. Bicchi, M. Morando and A. Ruggiero (2009b). Coopération internationale: la réalisation d'Expositions Thématiques comme moyen d'éducation au développement durable environnemental, In: Actes du $5^{\mathrm{e}}$ Colloque Interuniversitaire Turin-Sahel, Bobo- Dioulasso, Burkina-Faso 10-12.04.2009, 122-140.

Ghose, S. (2000). From hands-on to mind-on: creativity in science museums, In: Museums of Modern Science Nobel Symposium, S. Lindqvist (ed.), Science History Publications, USA, 117-127.

Goleman, D. (1995). Emotional intelligence, New York, Bantam Books, 352 pp.

Robson, C. (2005). Real World Research. 2nd edition, Blackwell, 599 pp.

Silvermann, D. (2004). Come fare ricerca qualitativa, Roma, Carocci, 375 pp.

Vomero, V., and L. Merzagora (2001). Hands on vs mind on. Sistemi di comunicazione nelle esposizioni scientifiche, Museologia Scientifica, 18, 25-42.

Wagensberger, J. (2000). In favour of scientific knowledge: the new museums, In: Museums of Modern Science Nobel Symposium, S. Lindqvist (ed.) Science History Publications, USA, 112, 129-138.
^Corresponding author: Alessandra Magagna, Università di Torino, Dipartimento di Scienze della Terra, Torino, Italy; email: alessandra.magagna@unito.it.

(C) 2012 by the Istituto Nazionale di Geofisica e Vulcanologia. All rights reserved. 